\title{
REVISTAMARACANAN
}

\section{Os caminhos da biografia: teorias, métodos, experiências e possibilidades}

Resenha de:

AVARO, Nora; MUSITANO, Julia; PODLUBNE, Judith (orgs.). Un arte vulnerable: la biografia como forma. Rosario: Nube Negra, 2018. 338p.

João Muniz Junior*

Universidade Estadual Paulista - Campus Assis,

Brasil

Recebido em: 24 abr. 2019.

Aprovado em: 25 abr. 2019.

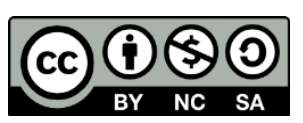

Palavras-chave: Biografia. Teoria. Experiência Narrativa.

Keywords: Biography. Theory. Narrative Experience.

O presente trabalho foi realizado com apoio da Coordenação de Aperfeiçoamento de Pessoal de Nível Superior - Brasil (CAPES) - Código de Financiamento 001.

* Doutorando em História, com bolsa da CAPES, pela Universidade Estadual Paulista - Campus Assis (UNESP/Assis). Mestre e graduado em História pela UNESP/Assis. (joaomuniz_jr@hotmail.com)

CV Lattes: http://lattes.cnpq.br/6369667028646263 
A obra Un arte vulnerable é resultado de um colóquio homônimo sobre escrita biográfica. O evento foi idealizado e organizado pelas autoras do livro na Faculdade de Humanidades e Arte, na cidade de Rosario, Argentina, entre os dias 11 e 12 de novembro de 2016. As organizadoras se mostram convictas de que não há teoria biográfica que possa suplantar a derivada da atividade própria de cada experiência narrativa de uma vida. Vale notar que tal convicção, mola propulsora para o evento acadêmico, é perceptível nos textos que compõem o livro. Os artigos reunidos são reescritas das apresentações dos convidados para o colóquio, com acréscimos advindos de discussões suscitadas durante o encontro acadêmico. ${ }^{1}$

A obra conta com dezoito capítulos distribuídos em quatro seções temáticas, que não são estanques, mas comunicam-se na medida em que a leitura flui. A primeira parte intitulada "Teorias em ato", ${ }^{2}$ apresenta uma gama variada de discussões como a questão da onisciência do biógrafo nas formas tradicionais de narrativas de vida; as possibilidades uma escrita biográfica com fronteiras permeáveis a infiltrações de incursões autobiográficas; o fetiche referencial; as ligações entre vida e obra; o método biográfico; o dispositivo da escrita; as conexões entre a biografia e o ensaio.

Antonio Marcos Pereira é autor do primeiro ensaio e toma Flaubert's Parrot, de Julian Barnes, como linha de partida para questionar os limites entre biografia e ficção em uma rica abordagem sobre duas veredas metodológicas: a biografia canônica e a biografia processual. A primeira obedece à tradição de manter o máximo possível o biógrafo invisível na construção do texto. Já na biografia processual, o biógrafo deixa transparecer seu trabalho investigativo, as dificuldades de pesquisa, as disputas de memória. Enquanto a biografia canônica valoriza uma narrativa neutra, isenta de lacunas, a biografia como processo procura demonstrar os limites enfrentados pelo autor, as versões contraditórias. Antonio Marcos Pereira opta pelo segundo caminho, pois, para ele, as narrativas mais profundas seriam aquelas que possibilitam um estreitamento nos laços entre um leitor, o biógrafo e o biografado; o biografado e sua obra.

O que torna uma vida digna de ser narrada? É em reposta a esse questionamento que Carlos Surghi escreve o seu artigo valendo-se da hermenêutica de Wilhelm Dilthey para não só abordar de forma crítica os modelos biográficos que narram vidas teleobjetivadas como também as relações entre vida e obra. A análise instiga-nos a pensar sobre a "fascinação biográfica", conceito que permite avaliar o rompimento com aquilo que Antonio Marcos Pereira já havia identificado no capítulo anterior como biografia canônica. O texto é um convite para

\footnotetext{
${ }^{1}$ Ao todo, são dezoito autores que assinam os artigos, por economia optamos por não comentar dados básicos sobre formação, vínculos institucionais e linhas de pesquisa de cada um, por sinal, algo que poderia estar presente no livro. Em linhas gerais, a obra tem o mérito de reunir biógrafos e pesquisadores latino-americanos oriundos de Argentina, Brasil, Uruguai, Chile, que concentram seus estudos e atuações em áreas tais como literatura, ensaísmo, crítica literária, teoria literária e escrita biográfica.

2 Serão realizadas traduções livres tanto de expressões como de trechos da obra na medida em se fizerem presentes no texto desta resenha.
} 
deter-se em reflexões acerca da subjetividade do biógrafo: a faina investigativa, que gera uma obsessão incontrolável, um completar-se a si mesmo na medida em que se escreve sobre o outro.

O gênero biográfico, recorrentemente é ancorado numa aporia: ou se faz biografia ou se faz história. Há, portanto, uma tentativa, sempre frustrada, de se medir o teor biográfico e o ficcional de uma narrativa biográfica, na visão de Aldo Mazzucchelli. Em ritmo de ensaio e dotado de erudição, o autor realiza um exame das diferenças entre as concepções positivistas sobre documento e verdade em contraposição a ilusão do "texto puro", livre de qualquer referência, conforme alguns modelos pós-estruturalistas. O texto apresenta ainda uma interessante discussão sobre a questão do chamado "retorno do autor" e, valendo-se de ideias de Heidegger sobre o papel social da escrita, reflete sobre os avanços tecnológicos e os seus efeitos nos processos de subjetivação do autor.

Na sequência, Julieta Yelin parte de uma provocação: existem biografias de animais? A autora nega a possibilidade de tal empreendimento, e, para justificar, estabelece relações entre o pensamento de Foucault e Heidegger no que concerne a questão da linguagem como prova do mundo, como efeito da bios. A zoografia se encontra perante um entrave: os animais não falam e a exigência vocal do biografado é inegociável. Assim, a possibilidade de se escrever uma zoografia seria mediante uma linguagem adequada para se falar de outras linguagens e outras formas de vida.

Lorena Amaro Castro fecha o bloco teórico com uma análise enriquecedora das contribuições de Virgínia Woolf no tocante à biografia e autobiografia. É destacado o papel da biógrafa inglesa na quebra de paradigmas ao realizar experiências profícuas com o referencial e o ficcional. "Flush: uma autobiografia" seria um ótimo exemplo desse rompimento com os rígidos modelos pré-estabelecidos, já que Woolf, de uma só tacada, escreve uma autofiç̧ão sob o ponto de vista de um animal de estimação, no caso um cocker spaniel e ainda, se lança em um terreno dominado pelos homens, questionando, portanto, as normatizações sociais sobre gênero e hierarquia familiar.

"O romance do biógrafo", título da segunda seção, reúne textos de autores que publicaram biografias e aproveitam o espaço para compartilharem as experiências acumuladas ao longo desse processo. A ligação entre esse segundo bloco de textos e o primeiro é estabelecido por Irene Chikiar Bauer, biógrafa de Virgínia Woolf. O artigo expõe elementos da escrita biográfica de Bauer, como o uso da cronologia a fim de fugir das limitações temáticas que envolvem a biografada atendo-se ao seu fluxo de vida. Além da questão metodológica, é compartilhado com o leitor os desafios da pesquisa, da tarefa hercúlea de dar conta do enorme corpus documental e a difícil tarefa, autoimposta pela biógrafa, de se manter a distância da protagonista, a fim de não se envolver com a personagem cuja vida narrava.

Ana Inés Larres Borges relata a experiência de escrever a biografia da poetisa Idea Vilariño. Partindo do ceticismo de Jorge Luis Borges quanto às possibilidades de se efetivar os vínculos entre vida e obra, o texto problematiza não só esses limites, mas também a hegemonia estruturalista em sua faina antibiográfica. O mote do artigo em questão é pensar 
os dilemas e tensões entre vida e obra na junção de escrita da vida privada e da trajetória de um autor, ou seja, ponderar a velha demanda sobre a necessidade de se conhecer a vida para compreender a obra.

Carlos María Domínguez deixa claro que seu texto é muito mais uma reflexão sobre a experiência de escrever três biografias do que tratar de teorias sobre o gênero. São relatados os desafios inerentes, principalmente, à coleta de depoimentos. Diante das lacunas, das inconsistências e das contradições, o biógrafo se viu forçado a conjeturar a fim de não cometer enganos, propositais ou não. Cada uma das biografias apresentou desafios próprios que foram vencidos ou contornados por estratégias específicas para cada caso.

Osvaldo Baigorria encerra a segunda divisão da obra com o relato de como escreveu a biografia de Néstor Sánchez. O biografado desafiava uma narrativa de sua vida uma vez que o período mais importante de sua trajetória era envolto por em um breu de informações desencontradas ou faltantes. A saída, ao invés de romancear, foi elaborar uma narrativa conjetural, ou como o próprio autor classifica, uma "pós-autobiografia". O texto é um relato saboroso, permeado pelas confissões de subjetivação do biógrafo, que, na execução do projeto, pegou-se indagando sobre si mesmo. A experiência de subjetividade acabou gerando não um livro sobre Sánchez, mas com Sánchez, resultando em uma "ilusão referencial" ou "superstição realista".

A terceira seção do livro, "A vida em obra", é a reunião de leituras críticas sobre biógrafos e biografados. Nessa etapa do trabalho, os autores procuram refletir sobre as escolhas metodológicas e teóricas, sobre as estratégias narrativas, sobre as motivações dos biógrafos e os comportamentos de determinados biografados. É outra visão da operação biográfica, ${ }^{3}$ não mais sob o ângulo da subjetividade de quem escreveu uma história de vida, mas de quem analisa os modos pelos quais a vida de alguém foi colocada em forma escrita.

O elo entre a terceira subdivisão e a anterior é uma nova aparição de Osvaldo Baigorria. Todavia, não como autor de texto, mas como objeto de análise de Julia Musitano que se debruça sobre a biografia de Néstor Sánches. A pergunta seminal de Musitano é: o que levou o biógrafo a se interessar pelo biografado? Provavelmente, segundo o texto, porque Baigorria seria alguém fascinado pelo indivíduo nômade, aquele que prefere não pertencer a um só lugar. Assim, o biógrafo realiza com o biografado uma fusão, não autorizada, do seu eu com o outro, ou seja, aquilo que o próprio Baigorria admite ser uma pós-autobiografia.

Em seguida, Nieves Battistoni elege a biografia de Osvaldo Lamborghini escrita por Ricardo Strafacce para ser analisada. O curioso desse caso seria que Strafacce, com uma carreira dedicada ao exercício da advocacia, nunca havia escrito um livro até publicar a vida de Lamborghini. Apesar de o texto da biografia ser coordenado por uma cronologia rígida, há concessões narrativas que dão dinâmica ao texto, como flashbacks e fordwards, que geram

\footnotetext{
${ }^{3} \mathrm{O}$ conceito de operação biográfica procura realizar uma releitura da operação historiográfica de Certeau (CERTEAU, Michel de. A escrita da história. Rio de Janeiro: Forense-Universitária, 1982), mas a partir das demandas do gênero biográfico. Sobre o conceito de operação biográfica, ver: MUNIZ JUNIOR, João. Biografia e história em Raimundo Magalhães Junior: narrativas de panteonização e iconoclastia. São Paulo: Cultura Acadêmica, 2017, p. 105.
} 
tensão dramática e expectativa nas passagens de um capítulo para o outro. O uso da cronologia rígida teria como objetivo contrastar com a vida descontínua e nômade do personagem retratado, a fim de refutar os mitos de uma vida errática. Assim como ocorre com Baigorria, ocorre também uma síntese entre biógrafo e biografado, ou seja, uma narrativa com aspectos autobiográficos.

Patrício Fontana inicia o seu texto com uma reflexão sobre a ideia do "retorno do autor" e do sujeito nas últimas décadas para depois analisar a biografia de Silvina Ocampo de autoria de Mariana Enríquez. Questões importantes são levantadas sobre os limites entre perfil biográfico e uma biografia propriamente dita. O "perfil" seria uma forma de se esquivar de dar conta de uma biografia "total"? Quanto de totalidade seria necessário para que um texto seja considerado biografia e não um perfil biográfico? Patricio Fontana responde não só a essas indagações como também sobre as relações da biógrafa com o seu texto e sobre os limites e as características do gênero em si.

Analía Capdevila analisa a biografia escrita por César Aira sobre a vida de Alejandra Pizarnik cuja espinha dorsal é o estabelecimento das vinculações entre vida e obra da biografada. São expostas as dificuldades do biógrafo em romper com os clichês, mitificações e estereótipos que cercam a biografada. Para tanto, a trama é conduzida por um narrador sempre cauteloso, que prefere expressões como "pode ter sido" ou "deve ser assim" do que uma afirmação categórica.

Judith Podlubne se encarrega de perscrutar a biografia de Oscar Masotta assinada por Carlos Correa, amigo do biografado, que confessa não ser guiado por nenhum método de escrita de vida. São convidadas para o texto análises da crítica literária em articulação com concepções de Virgínia Woolf, David Hume, George Luckács e Theodor Adorno no tocante a temas relacionados ao fazer biográfico, aos entrecruzamentos entre biografia e ensaio, ensaio e retrato, a fim de concluir que o estudo de caso apresentado evidencia a maneira como a escrita de uma vida afeta o biógrafo.

A terceira etapa do livro é encerrada com um artigo de Marcela Zanin sobre a biografia de Rúben Darío escrita por Vargas Vila. Diferentemente de alguns biógrafos que desejam explicar a obra a partir da vida, Vila se propõe a estabelecer os vínculos entre obra e vida, às vezes, para constatar a dissonância entre ambas. Trata-se de uma biografia com mesclas de autobiografia em razão das relações, nem sempre harmoniosas, que o biografado manteve com o biógrafo. Segundo Zanin, mais do que mesclar a própria vida com a do biografado, Vila quer viver paralelamente a vida de Darío.

Em "Cenas biográficas", derradeira seção da obra, biógrafos contam suas vivências no exercício de suas atividades: as viagens para pesquisa de campo, os locais visitados em busca de inspiração ou coleta de documentos, arquivos e depoimentos, os pontos de partida e de chegada, os altos e baixos na experiência de narrar a história da vida de determinado personagem.

Mónica Szurmuk é biógrafa de Alberto Gerchunoff e usa o artigo para dar vazão à sua subjetividade com matizes de confissão, como ter aprendido a escrever biografia escrevendo 
uma biografia e também com base na leitura de outras histórias de vida; a forma como o desconhecimento e inexperiência com o gênero causou atrasos e grandes dificuldades na escrita que, por sinal, não estava sujeita a contratos, prazos; não sabia se a obra seria, inclusive, publicada ou se fosse, em qual língua, inglesa ou espanhola. O texto de Szurmuk permite, mais uma vez, evidenciar-se que o contato entre biógrafo e biografado acaba por levar a experiências de subjetivação.

Na sequência, Nora Avaro elabora um texto em que traz para a reflexão análises de autores que Ihe fazem companhia em Un arte vulnerable como Irene Bauer, Antonio Marcos Pereira, Aldo Mazzucchelli e Ana Larre Borges. Nora Avaro mescla as análises desses autores com a sua própria experiência de biografar Adolfo Pietro, com considerações acerca dos métodos de escrita utilizados: uma combinação antagonista de exaustividade monumental e liberdades interpretativas. A biógrafa encerra com reflexões sobre a escrita biográfica e os processos de subjetivação do biógrafo que acaba se fundindo à narrativa da vida que elegeu para contar.

Martín Pietro fecha a coletânea com um texto dividido em subtítulos que funcionam como placas indicativas do percurso realizado pelo biógrafo em sua empreitada de escrever a vida de Juan José Saer: pesquisa, levantamento de dados, arquivos, documentação, entrevistas e viagens para pesquisa de campo. É possível acompanhar não só as etapas preliminares para a escrita, mas as concepções do biógrafo sobre o gênero: necessidade do uso maciço de documentação e pesquisa, a importância atribuída ao contexto e às redes de sociabilidade do protagonista, e, por fim, a valorização de se estabelecer os vínculos entre a vida e a obra do biografado.

Un arte vulnerable descortina um panorama rico de questões e abordagens no tocante à biografia e autobiografia no espaço latino-americano. A contribuição da obra é no sentido de oferecer reflexões sobre essas formas de escrita e suas peculiaridades, como a de alimentar-se da literatura e ao mesmo tempo impor a barreira documental como forma de legitimar o seu discurso. É justamente esse caráter híbrido da (auto)biografia que lhe confere, a um só tempo, vulnerabilidade, insipiência, vigor e movimento. ${ }^{4}$

Cabe ressaltar que os artigos que compõem a coletânea não devem ser tomados como conjuntos estanques. De fato, os textos convidam a imaginar outros arranjos e articulações possíveis. A título de exemplo, Nora Avaro estabelece relações com autores que assinam textos presentes na obra a fim de evidenciar as relações entre teoria e prática na escrita biográfica.

O livro apresenta importantes análises sobre temas candentes no tocante ao biografismo. ${ }^{5}$ Essa publicação evidencia a complexidade de tomadas de posição sobre as

\footnotetext{
4 Sobre a questão do hibridismo, ver: DOSSE, François. O Desafio Biográfico: escrever uma vida. São Paulo: EdUSP, 2009.

5 Sobre a noção de biografismo, ver: SILVA, Wilton C. L. Para além da ego-história: memoriais acadêmicos como fontes de pesquisa autobiográfica. Patrimônio e Memória, São Paulo, Unesp, v. 11, n. 1, p. 71-95, jan.-jun. 2015.
} 
relações entre vida e obra, as fronteiras entre literatura e biografia, a problemática da subjetivação do biógrafo, os vínculos entre biógrafo e biografado, os usos do arquivo, dos documentos e das entrevistas, os desafios da pesquisa e da escrita da vida de um personagem. Trata-se de uma obra essencial para quem estuda a escrita biográfica e autobiográfica, seus limites e as suas possibilidades. 